\title{
Evaluation of the energy demands for a floating O\&M-hub
}

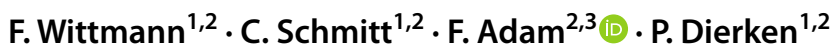

Received: 31 August 2020 / Accepted: 8 March 2021 / Published online: 1 April 2021

(c) The Author(s) 2021

\begin{abstract}
The Energyhub@Sea concept is one of the four research applications of the Space@Sea project funded by the EU's Horizon 2020 research program (GA number: 774253). The focus of this paper is the evaluation of the energy demands of an energy self-sufficient maintenance platform at the location of Helgoland in the North Sea. In view of this, a standardized modular floater was developed as an offshore wind operation and maintenance base, which in the following paper is referred to as an O\&M hub. The O\&M hub is intended to be equipped with accommodation facilities and various renewable energy infrastructure as well as spare parts logistics, enabling the platform to perform maintenance of offshore gearless wind turbines with a capacity of up to $10 \mathrm{MW}$. To be energy self-sustaining, an energy supply system for the hub was developed and simulated at a resolution of ten minutes by means of the Top-Energy simulation software, a commercial software tool. As a basis for the simulation, an approach for the automated determination of flexible load profiles, in resolutions of up to ten minutes was developed. This load profile generator creates load profiles on the basis of environmental conditions, technical characteristics, and expected behaviors of the inhabitants. On the basis of the generated load profiles, a first layout (referred to as baseline scenario) for the different components of the energy system was evaluated and tested through simulation. In a second step, three optimization scenarios were developed and simulated with regards to the financial feasibility of the Energyhub.
\end{abstract}

Keywords Energyhub@Sea·Space@Sea $\cdot$ Load profile generator $\cdot$ Multi-use platforms $\cdot$ Self-sufficient energy system

\section{Introduction}

With around 21,000 MW worldwide, there has been significant growth in the number and capacity of offshore wind turbines over the last decade (Whiteman et al. 2019). In addition to further growth of the installed capacity of ground-mounted offshore wind turbines, it is expected that the up-and-coming technology of floating wind turbines will lead to an enormous increase of capacity of approx. $12 \mathrm{GW}$ by 2030 (Rhodri et al. 2018). The increase in distances from the shoreline (Durstewitz et al. 2019; 4C Offshore 2020), logistics and transportation challenges are demanding and have to be addressed when developing potential solutions

F. Adam

frank.adam@uni-rostock.de

1 Energytechnology and Wind Engineering Division, GICON $\mathrm{GmbH}$, Leipzig, Germany

2 Energytechnology and Wind Engineering Division, GICON GmbH, Rostock, Germany

3 Chair of Wind Energy Technology, University of Rostock, Rostock, Germany for offshore operations. Consuming approx. 25-30\% of the total life-cycle-costs, operation, and maintenance services have almost the same financial impact as the wind turbines themselves (Miedema 2012; Lagerveld et al. 2014). In the future, an offshore on-site maintenance base will be an important counterpart to land-based ones in order to save transport costs and time required to service offshore wind parks (Röckmann et al. 2017). In this regard, Energyhub@ Sea (see Fig. 1) aims to offer a technical solution for an offshore wind operation and maintenance (O\&M) targeting low levelized costs of energy.

The Energyhub@Sea concept is one of the four applications of floating islands considered in the Space@Sea project. The major goal is to develop a cost-effective and energy self-sufficient maintenance platform for offshore wind farms. The design concept encompasses a multitude of additional functions of an O\&M hub for offshore wind services, serving as accommodation facilities for industrial personnel, housing of spare parts, and extracting renewable energy. The hub is intended to be equipped with a self-sufficient energy system that is renewable energy-based and independent from external fuel deliveries. In this way, the Energyhub 


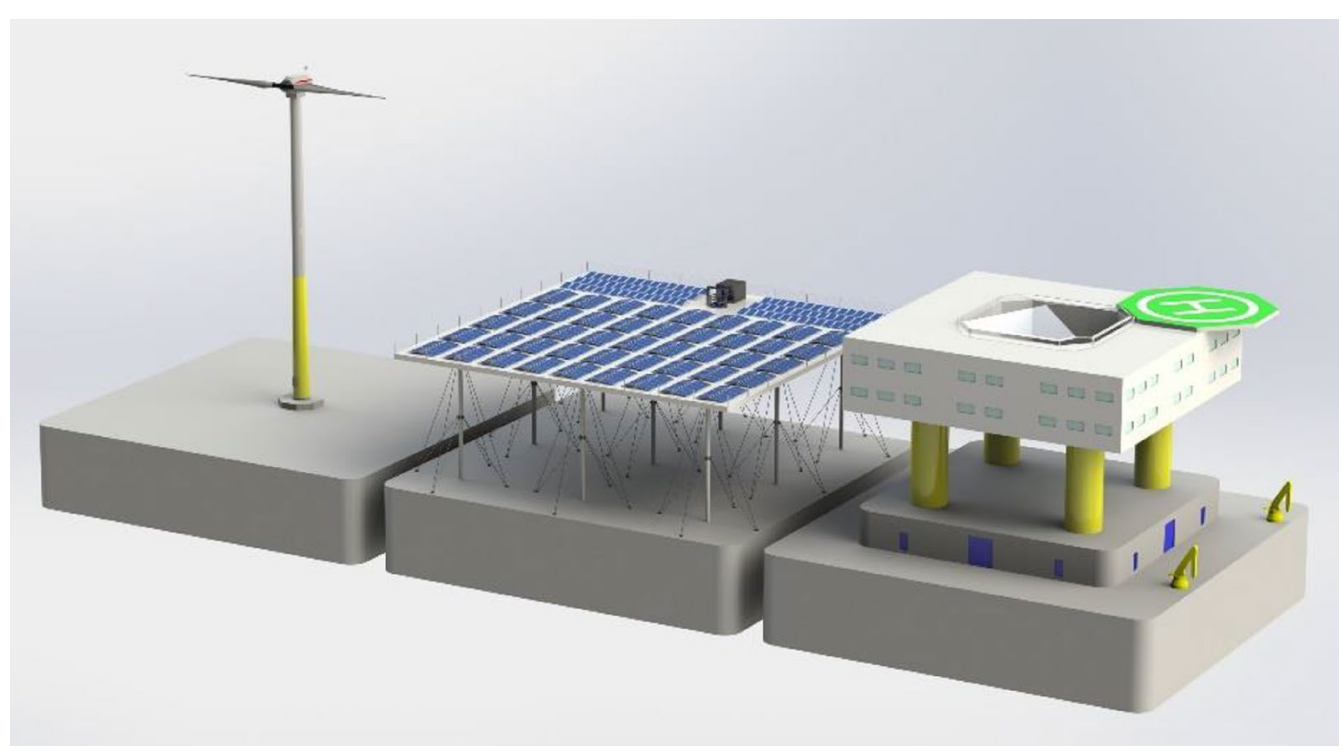

Fig. 1 Energyhub@Sea concept for North Sea location

is a completely independent unit. This raises the variety of conceivable use cases. As an example, the Energyhub could provide maintenance service for a remote wind park with direct conversion of electricity into fuel (gas or liquid) without grid connection.

The primary energy source of the hub will be a mediumsized wind turbine coupled with a photovoltaic (PV) system. A third source is intended to be wave energy converters. Due to the intermittent character of these energy sources, a time-dependent simulation of the system was done in order to design and evaluate a system configuration which is able to meet the hubs' demands. As the basis for the simulation, the hubs' energy demands were evaluated as load profiles. There are several approaches for the evaluation of demandside load profiles. The simplest approach is the use of standardized load profiles (Schieferdecker 1999; Fünfgeld and Tiedemann 2000), which are primarily used by energy suppliers for the rough estimation of regular household customers. Furthermore, there are a number of more sophisticated methods that evaluate load profiles on basis of measured data and action probabilities of devices (Stokes 2005) or activity profiles of household inhabitants (Widén et al. 2009; Metz 2014). Another option that allows very realistic results is described in (Pflugradt 2016). In this case, households are designed on basis of their equipment and their inhabitants. Therefore, the created load profiles are the result of the technical characteristics of the equipment (e. g. load and action profile of a dishwasher) and the desires and behaviors of the inhabitants. Most of the described tools have in common that they are not freely accessible; moreover, all of them are designed to evaluate load profiles for regular homes, houses and settlements, since they are mostly developed in the context of grid-related research projects. Due to this lack of accessibility and the very specific demands of the Energyhub, a specialized load profile generator was developed that creates load profiles on basis of environmental conditions, the technical characteristics of the hub and its equipment along with the expected behavior of the hub's inhabitants.

\section{O\&M-hub}

\subsection{Location}

During the Space@Sea project the Energyhub was developed as a multi-use approach for different geographic locations. Therefore, two scenarios located in the North Sea and in the Mediterranean Sea were evaluated. The present paper presents the results of the work done on the example of the North Sea scenario.

The considered location for the Energyhub lies between Norway and Scotland. The extreme on-site conditions are used as an experimental environment to define necessary loads for the energy system and stability criteria for the building structure of the multi-use approach. Furthermore, the North Sea is an area with development potential with 
respect to offshore wind farming. Especially in the context of floating wind turbines, the North Sea can be rated as an attractive location.

The expected average temperatures lie between minus ten and plus twenty degrees Celsius. In addition, the maximum expected wave height extends up to approx. twenty meters. Simultaneously, extreme conditions like heavy icing, snowfall, and long-lasting storms should be considered. An all-season service with a full crew, therefore, is impossible. Full service with the complete crew is reasonable only in summertime (April to October). In wintertime (November to March), the service is reduced to troubleshooting.

\subsection{Building design}

The design consists of four parts. The base is one of the standardized square shaped Space@Sea floaters with an edge length of $45 \mathrm{~m}$, a total height of ten meters and a calculated immersion depth of 4.7 to five meters. On top of the floater a storage hall that holds enough space for building technologies (such as heat pump, desalination, waste water treatment, buffer- and battery storage etc.), workspace and a sufficient stock of maintenance goods is located. As with the floater, the storage hall is intended to be built of reinforced concrete. The ground plan of the storage hall is square-shaped, as is the floater. The storage hall has an edge length of $32 \mathrm{~m}$ and a ceiling height of four meters, which leaves a surrounding quay with a width of $6.5 \mathrm{~m}$ for loading and transportation of goods on each side.

The third component is the accommodation building. As with the storage hall, the accommodation building has a square-shaped ground plan with an edge length of $32 \mathrm{~m}$. The accommodation building is supported by four columns, which represent the fourth compenent of the building. These columns have a diameter of four meters and a height of eleven meters and contain stairs, elevators and supply lines. The bottom of the accommodation building lies at a height of twenty meters above sea level. This meets the maximum expectable wave height for the North Sea. The columns provide enough space for a staircase, two elevators and supply lines for water, heating, cooling and electrical supply.

The accommodation building represents the most frequently used area of the O\&M-Module. Figure 2 displays the ground plan of the first floor of the accommodation building. As can be seen, the first floor can be described as a squareshaped loop surrounding a patio in its middle. The first floor is mainly occupied by the private cabins of the crew members, as it offers space for fifteen regular $\left(\sim 14 \mathrm{~m}^{2}\right)$ and four priority cabins $\left(\sim 33 \mathrm{~m}^{2}\right)$. Next to these private areas, the floor has four storage rooms that are mainly used for lodging purposes such as laundering and as storage of cleaning devices. Apart from that, the first floor offers social rooms (entertainment, fitness, etc.), a changing room, a technical room, and a medical room. In two of the floors, corners escape rooms are located. The escape rooms harbor lifeboats for emergency situations. If the module must be evacuated, the boats are directly launched to the sea.

Figure 3 displays the accommodation building's second floor. Similar to the first floor, a large share of the second floor's space is occupied by private areas. It offers space for eleven regular $\left(\sim 14 \mathrm{~m}^{2}\right)$ and two priority cabins $\left(\sim 33 \mathrm{~m}^{2}\right)$. In addition, the second floor houses the kitchen and dining area (kitchen, food storage, dining rooms), the technician's office, a conference room, a changing room, and two additional social rooms.

\subsection{Personnel on the Energyhub}

Being a permanently manned offshore platform, safe manning plays a vital role. Depending on the number and type of wind turbines which need to be maintained, the required number of personnel for maintenance services can vary. To define the performance of technician distribution at the appropriate levels of responsibility for the Energyhub, the number, and type of wind turbines to which the Energyhub can offer services is initially limited to 100 units of large-scale $10 \mathrm{MW}$ wind turbine generators (WTGs). After consultation with technical expertise from offshore O\&M sectors and knowledge gained from other experiences, the following rule-of-thumb assumptions can be made within this concept:

\subsubsection{Service technicians}

Based on estimated failure rates of the wind turbines, regular maintenance service, special oil, and coolant changes, and average transfer and waiting times, the required number of service technicians can be calculated as follows:

Service technicians $=$ round $(0.18 *$ number of $\mathrm{WTG}$ to maintain $)$

This depends strongly on the type of turbine as well as on the maintenance regulations issued by the wind turbine manufacturer. Other factors include the local environmental conditions (weather and waves) and the wind farm design, especially the contour of the field, the position of the O\&M hub in the field and the distances between the turbines. 


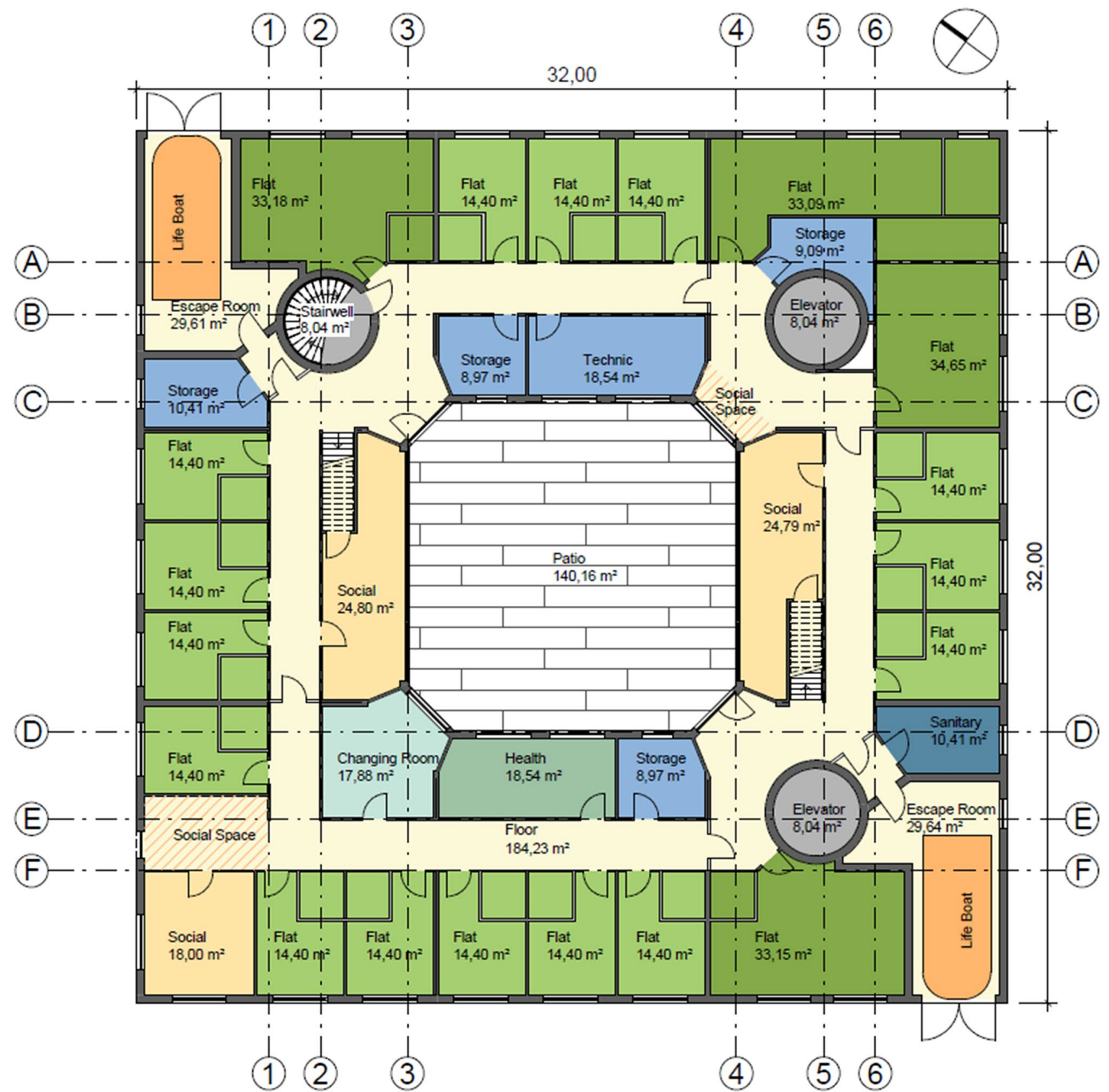

Fig. 2 First floor ground plan of the accommodation building

\subsubsection{Crew transfer vessel (CTV) crews}

Depending on the assumed number of 100 wind turbines, two CTV should be sufficient for transportation of personnel and typical maintenance equipment between the Energyhub and the wind farm. The number of crew members is set to 3 persons.

CTV boat crew $=$ round $(3 *$ number of service technicians $/ 10)$

\subsubsection{Office crew}

The office crew organizes all service and maintenance tasks on site, the material flow, and also the communication for technical issues.

Office crew $=$ round (number of service technicians/10) 


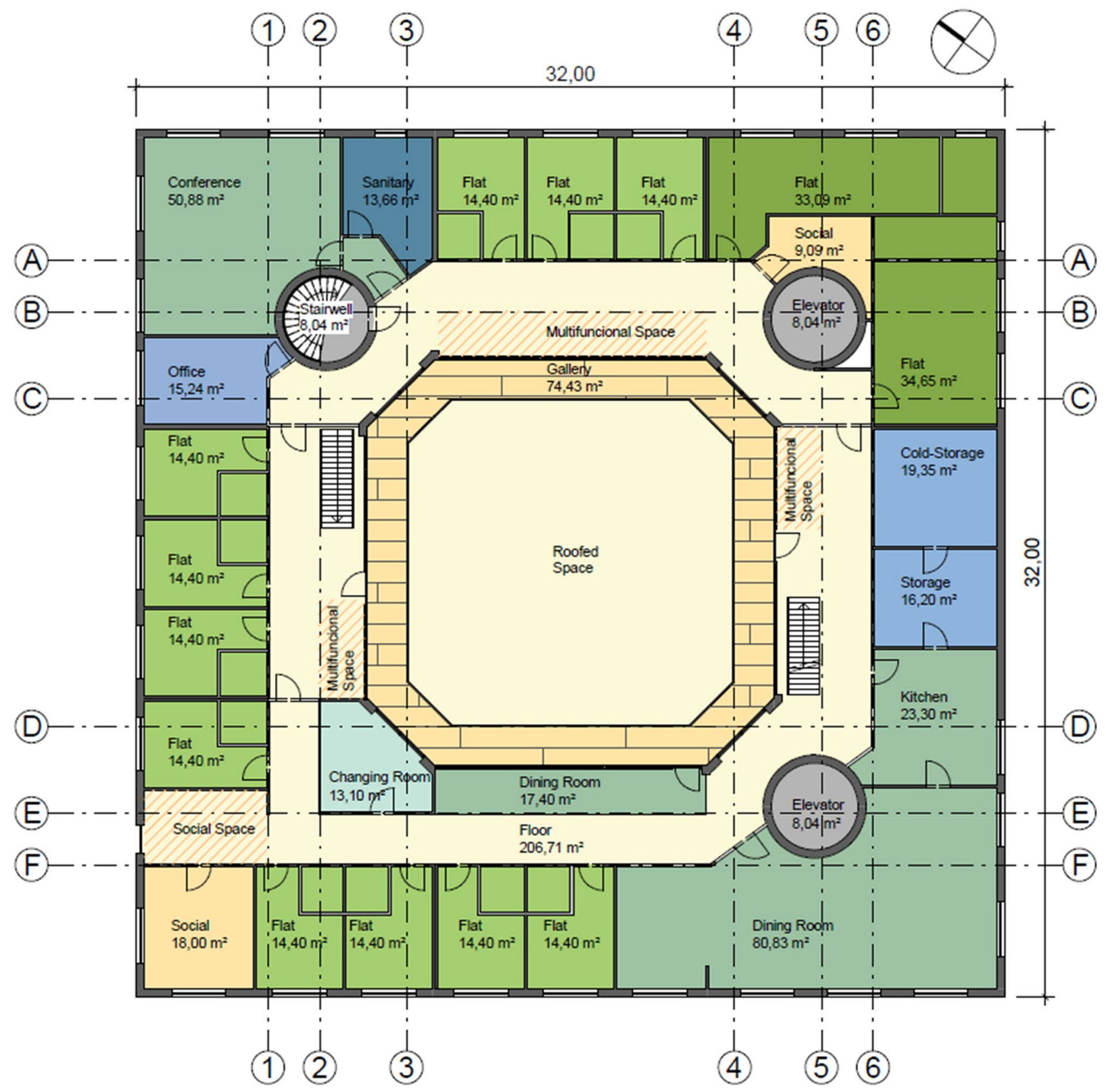

Fig. 3 Second floor ground plan of the accommodation building

\subsubsection{Board and lodging (B\&L) staff}

The B\&L staff guarantees the supply of food, clean linen, and work clothes for all persons living on the hub. They are also responsible for housekeeping, such as routines in the kitchen and canteen, laundry as well as for firefighting. The minimum team size is 3 persons; one extra staff member is needed for each additional seven persons on the hub.
All industrial personnel are accommodated onboard. However, daily working hours and days off for each personnel depend mainly on the region of operation. For instance, maximum continuous stay of 2 weeks is allowed for a crew who works more than $10 \mathrm{~h}$ per day according to German offshore working time regulations (Offshore-ArbZV). Therefore, a total of $12 \mathrm{~h}$ daily working hours, which includes $2 \mathrm{~h}$

Board and lodging staff $=3+$ round (number of (service technicians + ship crew + office workers) $/ 7$ ) 
Table 1 Personnel for operation in the North Sea

\begin{tabular}{llll}
\hline Personnel & Tasks & Number \\
\cline { 3 - 3 } & & Summer & Winter \\
\hline Service technician & Maintenance and repair & 12 & 6 \\
Extra service technician & Changing fluids or battery packs & 6 & 0 \\
CTV boat crew & Material and service crew transport & 6 & 3 \\
Office crew & Organization and management & 2 & 1 \\
Board and lodging staff & Housekeeping, kitchen and laundry & 6 & 4 \\
Sum & & 32 & 14 \\
\hline
\end{tabular}

of crew transfer and waiting time for the service technicians, with a maximum stay of 14 days was assumed in this report.

Accordingly, the number of personnel complements for the Energyhub at the North Sea site are described in Table 1. During harsh weather conditions in winter at the North Sea site, it may be inaccessible to the wind parks for a number of days due to wave, wind, and visibility conditions. Therefore, the number of required persons in winter is lower than that of summer. Approximately 32 persons are needed in summer to provide preventive maintenance for 100 wind turbines and 14 persons in winter for necessary urgent maintenance at the North Sea site, if the weather conditions permit. As shown in Figs. 2 and 3, the Energyhub was specifically designed for this crew size. In order to provide maintenance service for a larger wind park, either a different building design or several of the modules described should be applied.

\subsection{Energy system}

\subsubsection{Energy supply system}

In order to be as self-sufficient as possible, the Energyhub is intended to be equipped with a renewable energy-based supply system, which is independent from external fuel deliveries.

Figure 4 displays the hub's energy system. In the upper left corner, the hub's generation side consisting of a PVSystem, a wind turbine generator (WTG) and a wave energy converter (WEC) can be found. On the right side, the system's demands are listed. The hub exhibits thermal demands (space heating, space cooling, refrigeration of supplies, and hot water preparation) and electrical demands (devices, lighting, water supply and -desalination, ventilation, etc.). On the lower left side, the components for the generation of heat, cold, and water can be found. The storage systems are located in between the generation and the demand sides.
The hub's thermal demands are met through highly-efficient heat pumps, which use the surrounding seawater as an external heat source or heat sink. Therefore, a large share of the hub's thermal demands can be met through environmental heat. To raise the flexibility of the system, the hot water supply is additionally equipped with a buffer tank with an internal heat rod.

To ensure the energy system's ability to balance out supply and demand at all times, an electrical energy storage unit must be implemented. Due to its high efficiency, flexibility, and energy density, a Li-ion-battery was chosen.

\subsubsection{Load profiles}

2.4.2.1 Description of the load profile generator Due to the requirement that the hub is supplied by renewable energy sources only, the energy supply of the hub is very dependent on the time of day and the current weather conditions. In order to guarantee a reliable energy supply at any time, the entire system was simulated at a resolution of ten minutes over a span of three years. One basic requirement for the simulation of the system's behavior was the development of load profiles for the demands of the Energyhub. In order to address this task, a load profile generator was developed. The generator creates load profiles for behavior-dependent applications such as the usage of electric devices or the consumption of water as a Bottom-Up-model. This means the generator evaluates the behavior of each load (e.g. lighting, TVs, elevators, etc.) itself and accumulates them later on. The load profile generator uses a statistical method embedded in specifiable activity profiles.

The thermal demands of the building were determined by thermodynamic calculations on the basis of the environmental conditions (e.g. air temperature and solar radiation) and the Energyhub's building structure. Development of the applied calculation method was based on the German standard for the energetic assessment of buildings (DIN V 


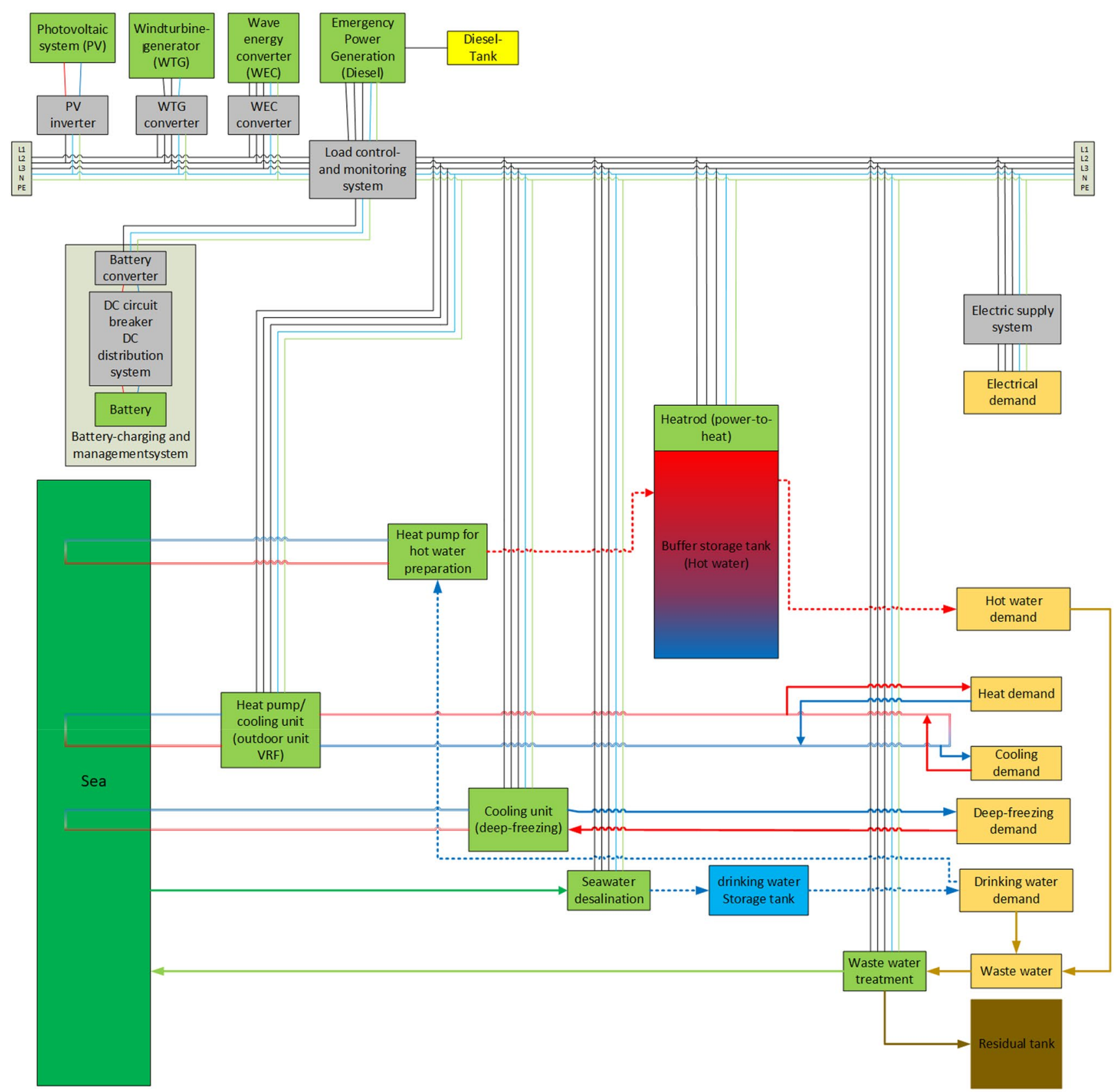

Fig. 4 Schematic diagram of the developed energy system (System components: electrical generation (upper left), building technologies (lower left), demands (right) and storage systems (middle)) (own graphic)

18599) and a number of other standards (e.g. DS 15748-2, VDI 2078).

\subsubsection{Function principles of the developed load profile} generator Due to the situation that the crews living at the
O\&M-Module are on board for 14 days, there will not be any weekends with reduced service necessary. This means that the course of the day will be more or less the same every day. As a result, it can be assumed that the daily energy demands will be quite similar. Even though this 
is the case, there will be certain differences with respect to the crew's behavior and the buildings interaction with its environment. These differences are very important for the simulation of the system, since they can lead to extreme load situations due to overlaps of different loads. In order to be able to design a more resilient supply system, these extreme load situations need to be taken into account. Therefore, it was decided to compose a load profile generator that can be used to automate the load profile generation process while simultaneously achieving a certain degree of flexibility. It is quite difficult to automate a realistic, flexible behavior. It was therefore decided not to define the load's behavior, but the probability of its action in the considered time interval. For this purpose, a structure is created that provides the user the possibility to define an operational probability for each load and hour of the day. The resulting aggregate of sets of probability profiles represents the expected behavior of the crew in the course of the day. By running the load profile generator, a probability generator that is based on a rectangular distribution is triggered at each time interval and for each load. The generator creates a value between zero and one with each action. Subsequently, the created values are compared to the operational probability of the current hour. If the created value is lower than the probability, the load will be triggered. In order to create a load profile with a resolution shorter than one hour, the same operational probability is applied several times per hour. In the present case (resolution of $10 \mathrm{~min}$ ) the operational profile was used six times per hour.

2.4.2.3 Generation of probability profiles The final shape of the load profile is very dependent on the probability profiles feeding the generator in the first place. Since there is no common standard for these profiles, the creation of the probability profiles was done on basis of empirical values.

The probability profiles for the simulation of the hub's behavior were developed in four steps.
Fig. 5 Visualization of the presence of crew members on board the hub in the course of the day. Off-board-crew (maintenance workers, transportation vessel crew), on-board-crew (technicians, lodging staff)

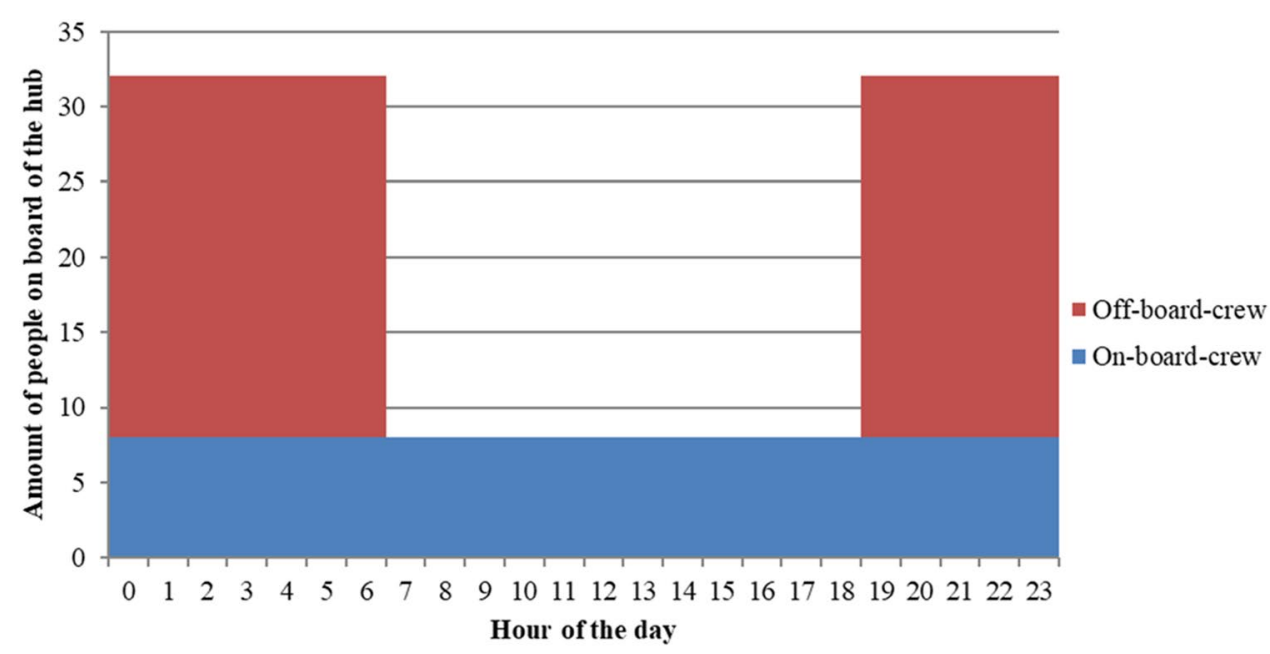

\begin{tabular}{lll}
\hline Consumer group & Examples for actions and loads belonging to the group: & Times: \\
\hline Kitchen/dishes & Kitchen lights, stoves, dishwasher & 5:00 a.m.-8:00 a.m.; \\
& & $10: 00$ a.m.-1:00 p.m.; \\
& & $4: 00$ p.m. $-10: 00$ p.m \\
Cabins & Light in cabins, hairdryer & $7: 00$ p.m. $-6: 00$ a.m \\
Social/entertainment & Light in social rooms, fitness, TV & $7: 00$ a.m. $-11: 00$ p.m \\
Office/work & PCs, monitors & $7: 00$ a.m.-6:00 p.m \\
Dining & Lights & $6: 00$ a.m. $-7: 00$ a.m \\
& & $12: 00$ p.m. $-1: 00$ p.m \\
Cleaning/laundry & Lights, washing machine, dryer, vacuum cleaner & 6 p.m.-8. $\mathrm{m}$ \\
Storage hall & lights, cranes & $7: 00$ a.m. $-5: 00$ p.m \\
Water supply & Desalination, wastewater treatments, water supply system & $6: 00$ a.m. $-7: 00$ p.m \\
Hygiene & Lights, showers & $12: 00$ a.m. $-11: 00$ p.m \\
& & $5: 00$ a.m.-6:00 a.m \\
\hline
\end{tabular}

Table 2 List of consumer groups including both examples for actions/loads that are arranged together and times the groups are expected to be triggered 
Fig. 6 Qualitative visualization of the schedule resulting from the considered action groups

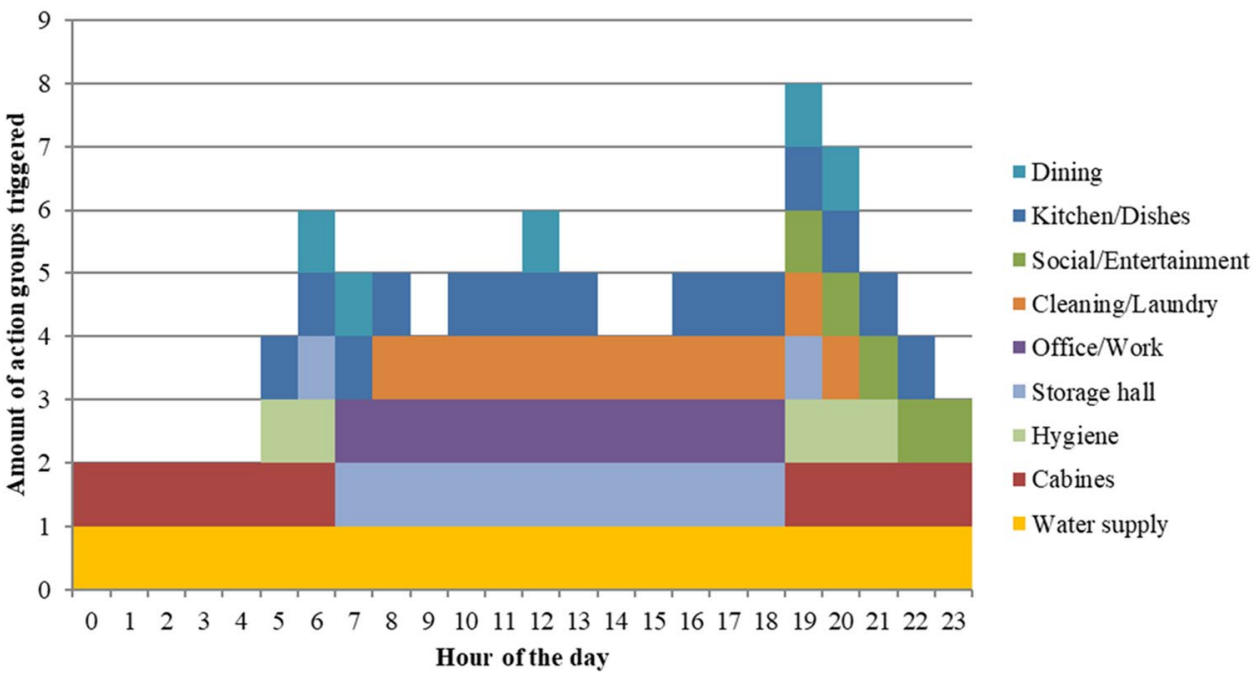

The first step was to determine which time and with how many people the hub would be occupied. It was decided that it could be distinguished between two groups of crew members: the members that leave the hub for work during day time (off-board-crew: maintenance workers and transportation vessel crew) and the members that stay on board all the time (on-board-crew: technicians and lodging staff). As mentioned before, it can be considered that the off-board-crew has a twelve-hour shift every day. Taking this into account, it was decided that the off-boardcrew should leave the hub each morning at 7:00 a.m. and return at 7:00 p.m. Resulting from these assumptions, the occupancy of the hub would appear as shown in Fig. 5. Following the logic that a larger group of people leads to higher energy demand, it can be assumed that the peaks of energy consumption should be expected in the morning just before the off-board-crew leaves and during the time in the evening after their return. During daytime, lower energy consumption can be assumed.

The second step of the development process was to determine at which times which kinds of loads and actions are likely to happen. To simplify this process, the various loads were arranged into consumer groups. As a result, a first rough schedule for a regular day onboard the hub was developed. Table 2 lists which groups were formed out of which types of loads and during which times it was considered they were likely to be in action. The considered times are essentially based on experiences. For example, a kitchen and its devices are in action when somebody is preparing food. Most people eat three times a day-once in the morning, once around noon, and once in the evening. As a result, the action times for the kitchen were chosen to be in the early morning, before noon, and in the afternoon.

Figure 6 visualizes the developed schedule in a qualitative way. It provides a first impression of the shape of the final load profile.

During the third step, the actual equipment of the Energyhub was defined along with its technical characteristics and the likelihood of each load being in action during a certain time of the day. As a result, a probability profile with a resolution of one hour was determined for each load on board the Energyhub. The equipment of the hub is very much dependent on the number of crew living onboard. In the present case, 32 equally-equipped private cabins along with common areas (e. g. kitchen, dining, and social rooms, cold-storage) suitable for a crew of 32 people were assumed. Figure 7 depicts the connection between the hourly operation probabilities (Figure A) and the cumulated load profile (four stoves) that are produced by running the generator (Figure B). Each operation profile is queried several times per hour, as can be seen from the flexible behavior of the devices in Figure B.

2.4.2.4 Resulting profiles Figure 8 depicts the evaluated load profile of the year 2017, subdivided into demands for deep-freezing, room cooling, electrical demands, room heating, and hot water preparation. The diagram shows a step in the height of the load peaks between the summer and the winter period which is caused by the reduction of the crew size during winter due to the rough weather conditions during this season. During the winter period, the load peaks 


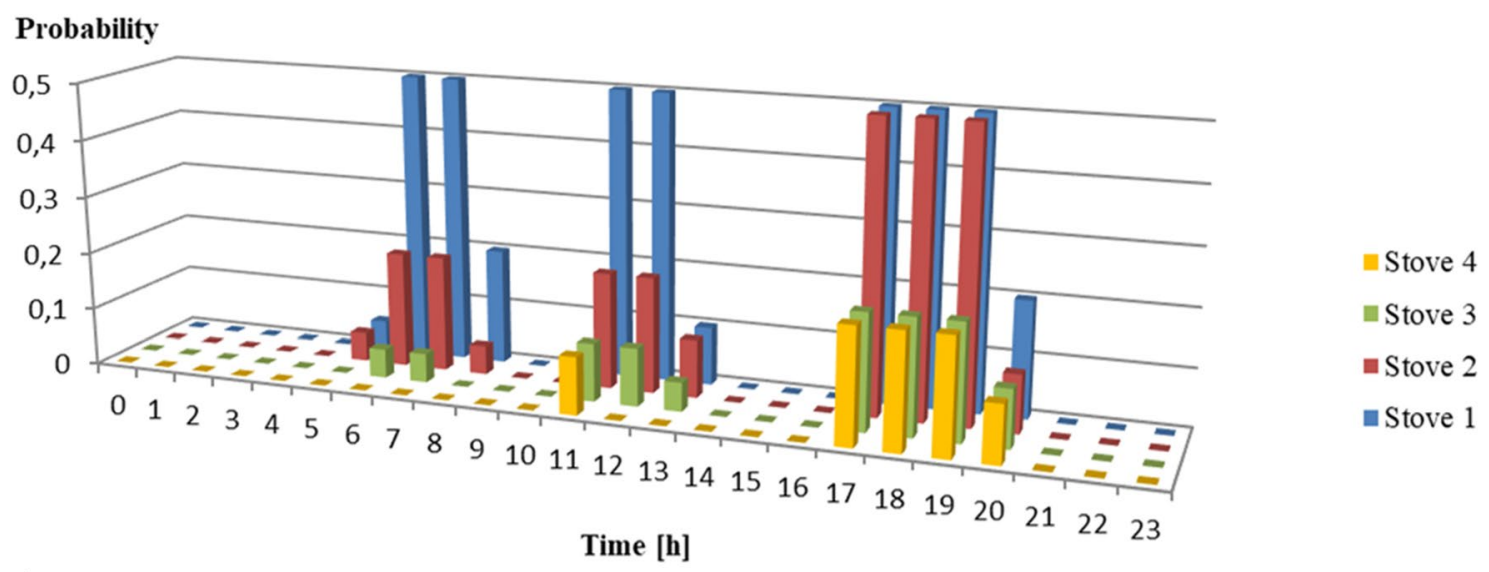

A

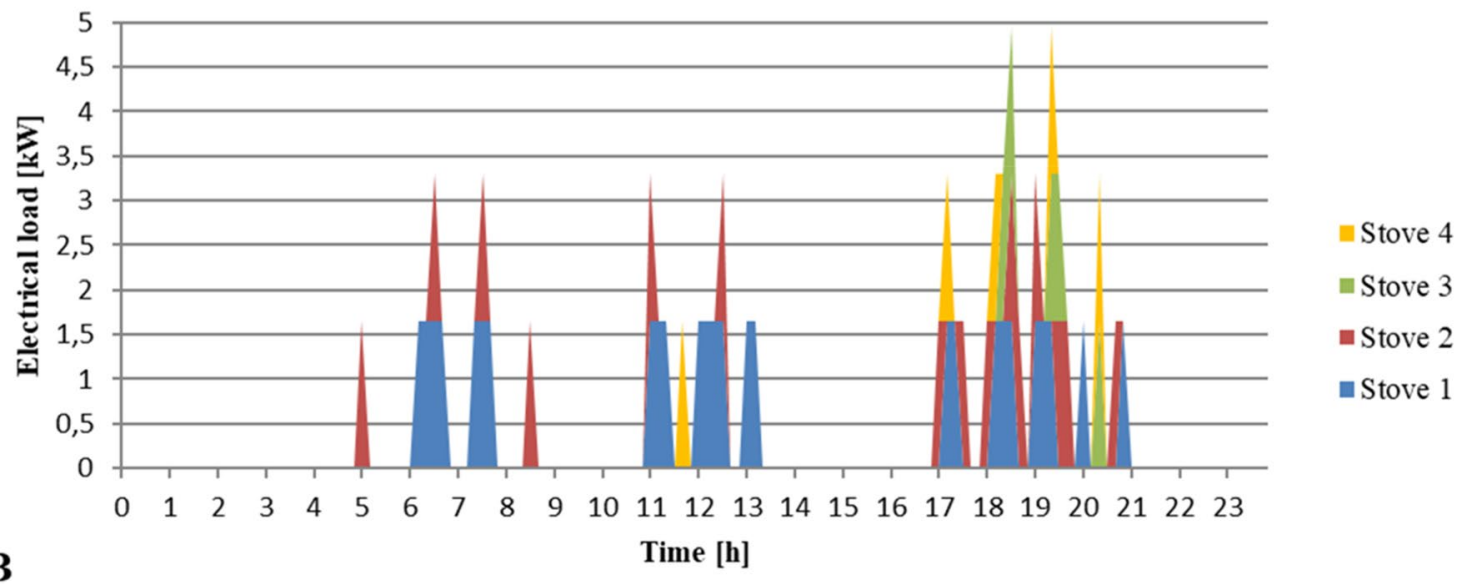

Fig. 7 Comparison of the probability profiles (a) and the resulting load profiles (b) of the four stoves in the kitchen of the O\&M module

extend to approx. $130 \mathrm{~kW}$. During the summer period, the load peaks reach approx. $155 \mathrm{~kW}$.

To obtain a better impression of the system's behavior, it can be useful to take a closer look at a smaller time interval. Figures 9, 10, 11 display load profiles of the North Sea scenario over a week in winter, during the transitional period, and in summer. The behavior of the demand for deepfreezing (grey) is the same over the entire year. Regarding room conditioning, there is in fact no real demand for cooling at the chosen location. The load profile for electrical energy (blue) has a similar structure every day throughout the course of the year, even if the total energy demands are higher in summer (due to the bigger crew). This structure exhibits three main peaks in the morning, at noon, and in the evening. The demands for heating (green) assume the largest share of the energy demands. The demands are the highest during day due to the lower need for ventilation at night. In the course of the year, the heating demands exhibit the largest differences. The demands are high in winter and low in summer. The heating demands in summer result from the relatively high nominal room temperature of 21 degrees Celsius and the relatively low-temperature level at the North Sea. The transmitted air needs to be conditioned for almost the entire year. The demands for hot water are focused on the mornings and evenings when the hub is fully occupied.

Figure 10 displays the last days of March and the first days of April. This time period is especially interesting, as it represents the transition between the winter and summer periods. This means the number of people living on the hub changes from 14 to 32 , which is the reason that the total 


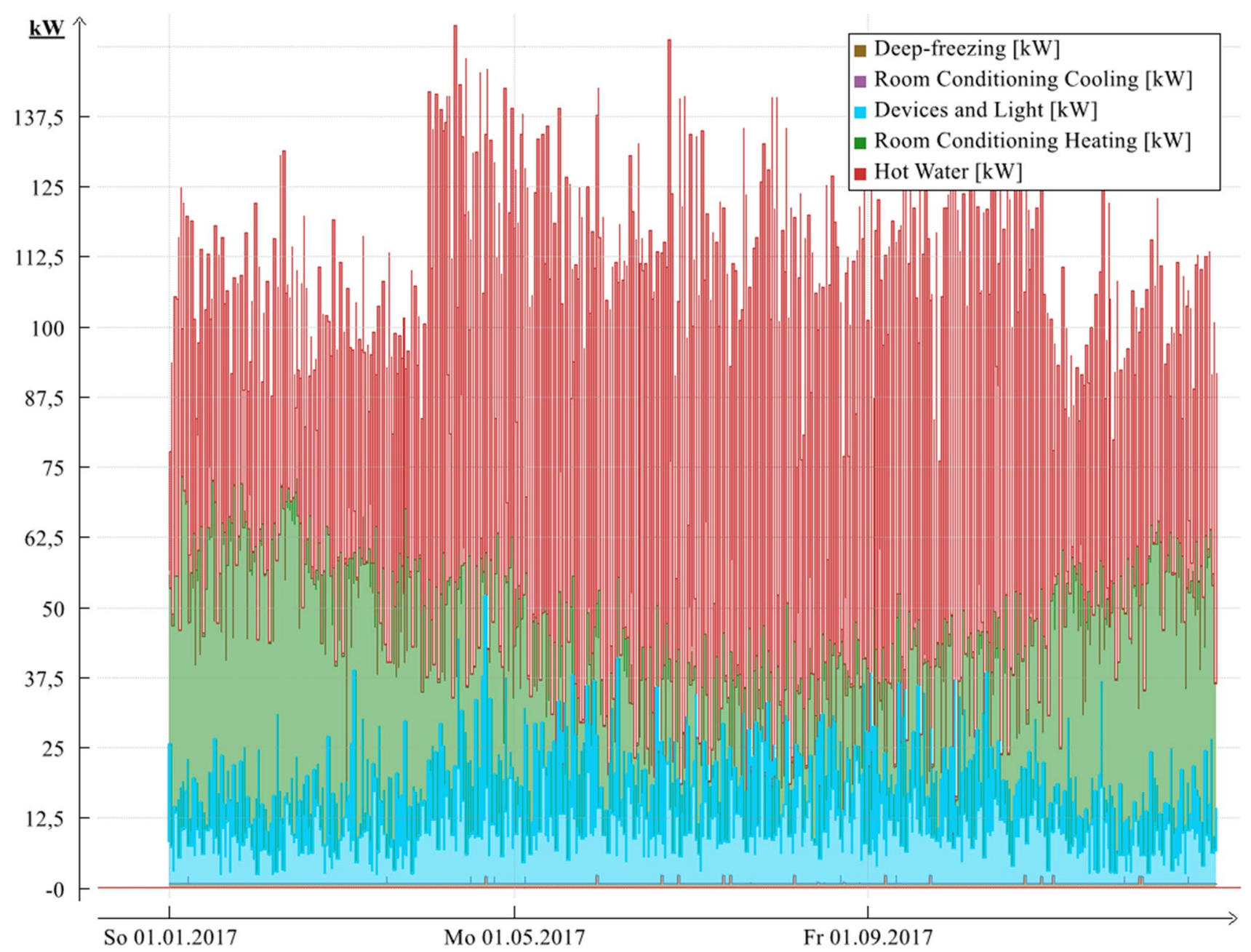

Fig. 8 Load profile for the year 2017. The profile is subdivided into demands for deep-freezing (brown), room cooling (purple), devices and lights (blue), room heating (green), and the preparation of hot water (red)

energy demands in the summer period are much higher than in the winter period.

Figure 11 displays a week during summer period. In total, the demands are relatively low due to the low demands for heating. The electrical demands and the demands for the preparation of hot water are higher than in the winter period due to the higher number of crew.

\subsubsection{Energy demands}

Table 3 displays the energy demands of the Energyhub for the years 2017, 2016, and 2015. The demands are divided into the component's devices and light, heating, cooling, and deep-freezing. For each component, the absolute value of the energy demands as well as the share of the total demand is provided. The electrical demands are further subdivided into the categories light, devices, and ventilation system.

Figure 12 visualizes the proportion of the different demands indicated in Table 3 in percent.

The energy demands for devices can be further subdivided into four device groups. The device group "living \& entertainment" includes devices like TV-screens, personal laptops, fitness devices and elevators. The group "kitchen \& lodging" consists of all the demands for cooking and housekeeping purposes. The device group "work" combines the demands for daily working processes including office devices, forklifts, and cranes. The group "water supply" includes desalination along with wastewater treatment and 


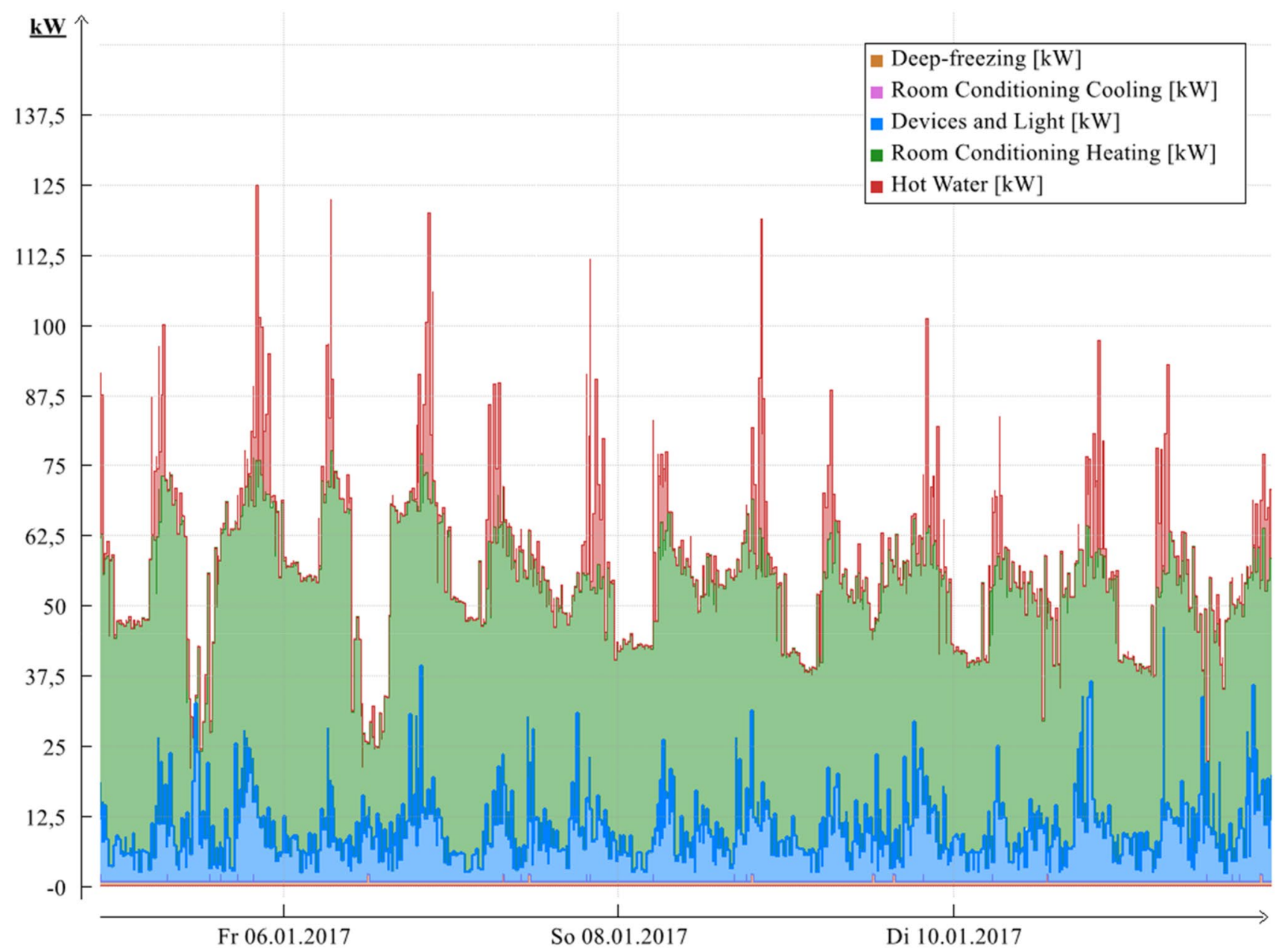

Fig. 9 Batch plot of the load profile of the North Sea scenario over a week in January 2017 (winter). The profile is subdivided into the demands for deep-freezing (brown), room cooling (purple), devices and lights (blue), room heating (green), and the preparation of hot water (red)

the demands of the water supply system. Table 4 displays the energy demands of the four groups in kilowatt hours and their proportion of the total demand of the devices in percent. It can be observed that the demands for "kitchen \& lodging" and "water supply" each comprise almost one-third of the total demand, whereas "living \& entertainment" and "work" share the last third almost equally.

By combining the demand groups "living and entertainment", "kitchen and lodging" and the illumination of the accommodation building, the accommodation building can be compared to a regular house. The electrical demands for this combination lie at approx. 49 megawatt hours per year. This equals approx. 13.2 regular households with three inhabitants $(3,700 \mathrm{kWh} / \mathrm{a})$. These still quite high demands for 32 inhabitants can be explained by the fact that the described combination includes a fitness studio, an elevator and a canteen.

\subsubsection{Resulting layout}

By analyzing the generated load profiles, it was possible to derive the necessary dimensions of the systems components. Initially, the requirements on the building equipment were evaluated. Table 5 displays the maximum loads of the generated load profiles, divided into heating, cooling, hot water preparation, and deep-freezing. These maximums can be used as guide values for the required dimensions of the building technology components to enable a simulation of 


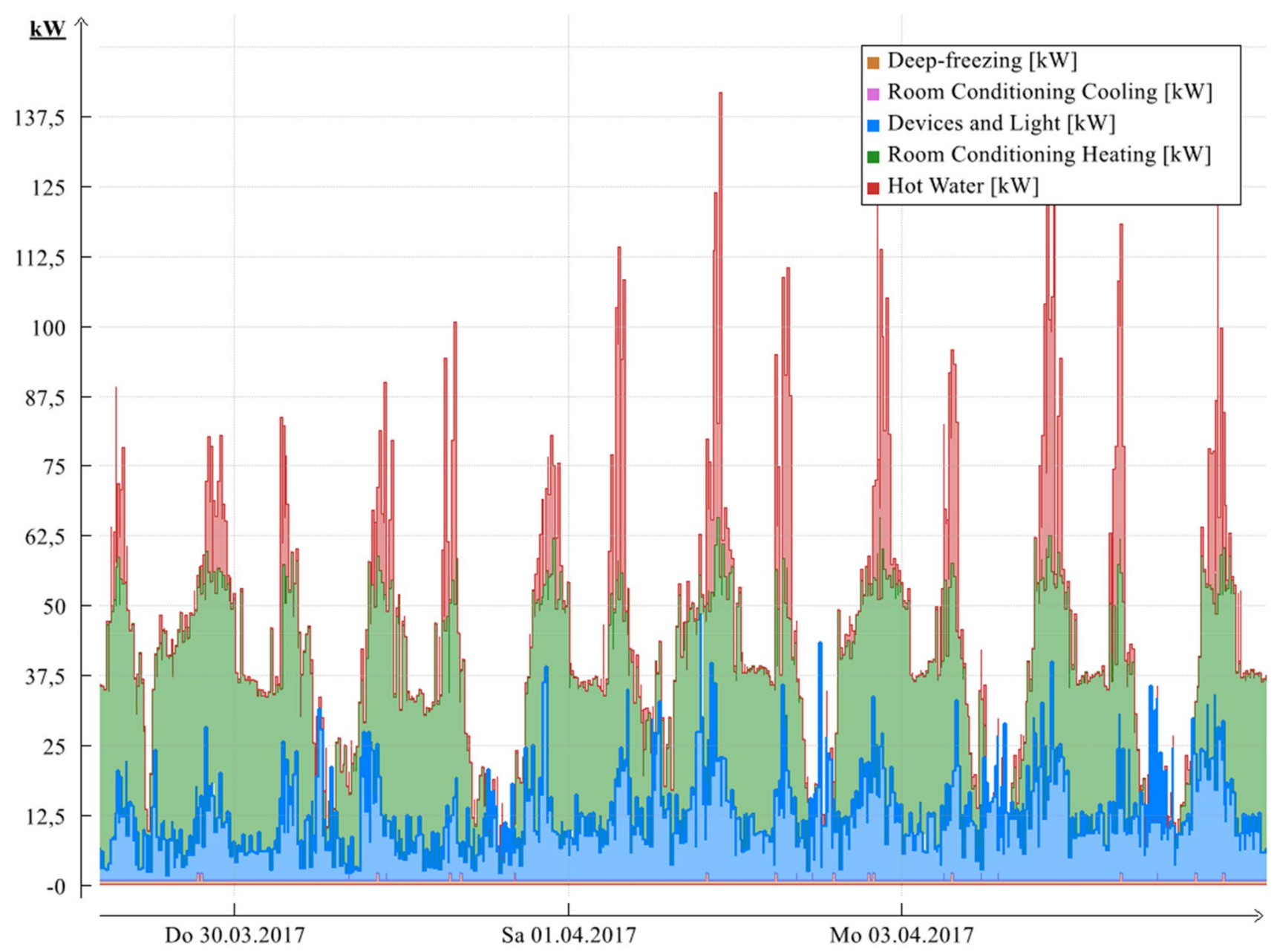

Fig. 10 Batch plot of the load profile of the North Sea scenario over a week in May 2017 (transitional period). The profile is subdivided into the demands for deep-freezing (brown), room cooling (purple), devices and lights (blue), room heating (green), and the preparation of hot water (red)

\section{Simulation of the energy system}

parameters of the components were chosen to be approx. $15 \%$ higher than the maximums resulting from the evaluated load profiles. Nevertheless, the layouts evaluated this way should not be taken as a final technical sizing or standard conformity, since the layout processes described in design standards are usually based on the most extreme conditions a component has to encounter. The readiness level of the Energyhub does not yet meet the requirements of detailed technical planning.

*Circa $15 \%$ extra

**The application of a hot water storage tank helps to temporally decouple the hot water preparation
On basis of the gathered information, the systems behavior was simulated for a baseline scenario and three optimization scenarios. The simulation was done by means of the Top-Energy commercial simulation software. Top-Energy is a software-solution for the modelling and linear optimization of decentralized energy systems. It can be used for the energetic and economic assessment of supply systems for electricity, heat, cold, compressed air, and steam. Within Top-Energy, each component of the system is reproduced in the form of a digital twin. The components can be parametrized as desired and fed with external time series (e.g. 


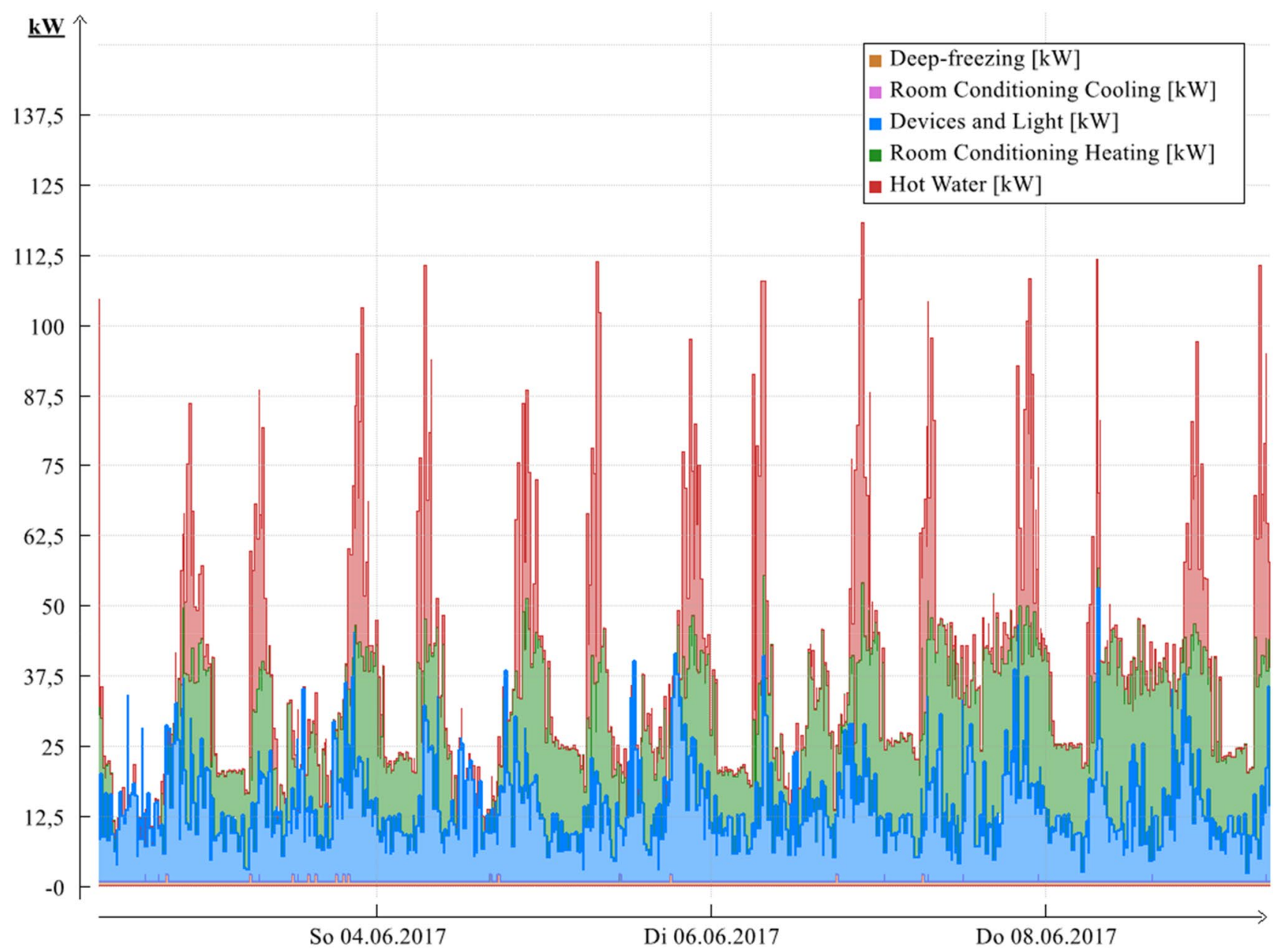

Fig. 11 Batch plot of the load profile of the North Sea scenario over a week in June 2017 (summer). The profile is subdivided into the demands for deep-freezing (brown), room cooling (purple), devices and lights (blue), room heating (green), and the preparation of hot water (red)

Table 3 Energy demands for the years 2015-2017. The electrical demands are subdivided into their components

\begin{tabular}{lrlrrrl}
\hline Load groups & \multicolumn{1}{c}{2015} & & 2016 & \multicolumn{3}{c}{2017} \\
\hline Devices and light [MWh/a] & 99.15 & $27.10 \%$ & 99.21 & $27.00 \%$ & 99.16 & $26.80 \%$ \\
Room conditioning heating [MWh/a] & 217.56 & $59.50 \%$ & 219.43 & $59.70 \%$ & 222.44 & $60.10 \%$ \\
Room conditioning cooling [MWh/a] & 0.05 & $0.00 \%$ & 0.07 & $0.00 \%$ & 0.00 & $0.00 \%$ \\
Hot water [MWh/a] & 42.71 & $11.70 \%$ & 42.84 & $11.60 \%$ & 42.68 & $11.50 \%$ \\
Deep-freezing [MWh/a] & 6.15 & $1.70 \%$ & 6.18 & $1.70 \%$ & 6.10 & $1.60 \%$ \\
Total energy demand [MWh/a] & 365.63 & $100 \%$ & 367.72 & $100 \%$ & 370.38 & $100 \%$ \\
Electrical demand light [MWh/a] & 22.24 & $22.40 \%$ & 22.16 & $22.30 \%$ & 22.28 & $22.50 \%$ \\
Electric demand devices [MWh/a] & 75.88 & $76.50 \%$ & 76.01 & $76.60 \%$ & 75.85 & $76.50 \%$ \\
Electric demand ventilation system [MWh/a] & 1.03 & $1.00 \%$ & 1.03 & $1.00 \%$ & 1.03 & $1.00 \%$ \\
Total Electrical Demand [MWh/a] & 99.15 & $100 \%$ & 99.21 & $100 \%$ & 99.16 & $100 \%$ \\
\hline
\end{tabular}




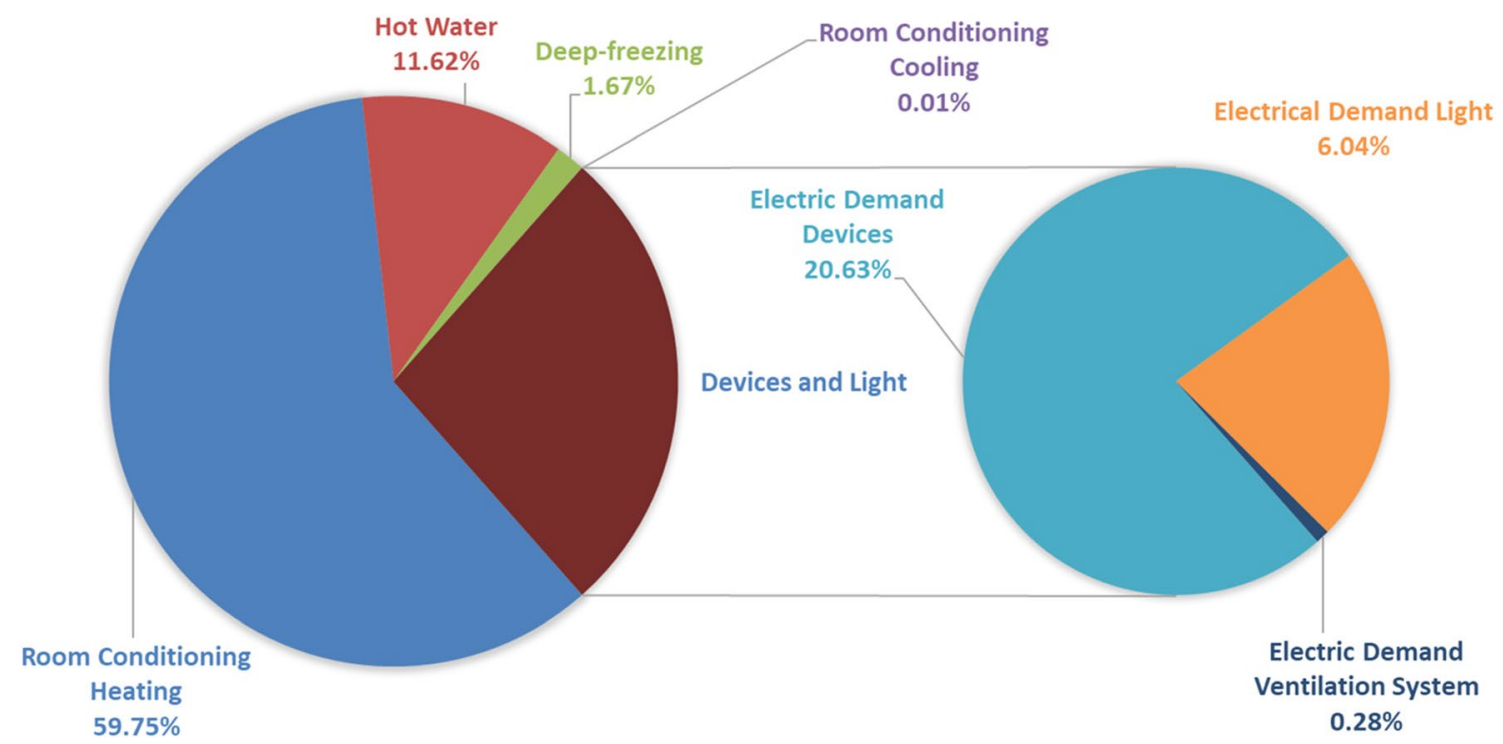

Fig. 12 Visualization of the distribution of the energy demands of the North Sea O\&M module on the basis of average demands of 2017, 2016, and 2015. The electrical demands are subdivided into devices, light, and ventilation

Table 4 Subdivision of the North Sea scenarios energy demands for devices in the four device groups: living and entertainment, kitchen \& lodging, work, and water supply, 2015-2017

Table 5 Maximum loads of the various energy demands derived from the load profiles over the years 2017, 2016 and 2015

\begin{tabular}{lllllll}
\hline Device groups & 2015 & & 2016 & \multicolumn{3}{c}{2017} \\
\hline Living and entertainment [MWh/a] & 14.25 & $15.50 \%$ & 14.16 & $15.40 \%$ & 14.25 & $15.50 \%$ \\
Kitchen and lodging [MWh/a] & 31.33 & $34.00 \%$ & 31.18 & $33.80 \%$ & 31.33 & $34.00 \%$ \\
Work [MWh/a] & 14.92 & $16.20 \%$ & 15.21 & $16.50 \%$ & 14.92 & $16.20 \%$ \\
Water supply [MWh/a] & 31.67 & $34.40 \%$ & 31.67 & $34.30 \%$ & 31.67 & $34.40 \%$ \\
Total energy demand [MWh/a] & 92.16 & $100 \%$ & 92.22 & $100 \%$ & 92.16 & $100 \%$ \\
\hline
\end{tabular}

\begin{tabular}{|c|c|c|c|c|c|}
\hline \multirow[t]{2}{*}{ Maximum Loads } & \multicolumn{3}{|c|}{ North Sea Scenario } & \multirow[t]{2}{*}{ Maximum } & \multirow[t]{2}{*}{ Layout* } \\
\hline & 2015 & 2016 & 2017 & & \\
\hline Room conditioning heating $[\mathrm{kW}]$ & 65.10 & 65.70 & 67.20 & 67.20 & 77.00 \\
\hline Room conditioning cooling $[\mathrm{kW}]$ & 38.30 & 39.10 & 0.00 & 39.10 & 45.00 \\
\hline Hot water preparation $[\mathrm{kW}]$ & 111.40 & 99.30 & 110.40 & 111.40 & 128.00 \\
\hline Deep-freezing [kW] & 2.10 & 2.10 & 2.10 & 2.10 & 2.40 \\
\hline
\end{tabular}

load profiles, weather data) in order to meet the local conditions to the greatest extent possible. Figure 13 depicts the simulation framework for the baseline scenario.

The baseline scenario consists of a PV-system that is mounted on top of an additional floater, a middle-sized wind energy converter that is installed on an additional floater as well and a waver energy converter (as shown in Fig. 1).

As a result of the simulation, the necessary size of the energy storage system was determined as a battery with a storage capacity of $700 \mathrm{kWh}$ and a maximum charge/discharge power of $215 \mathrm{~kW}$. In addition, it was observed that only $10.6 \%$ 


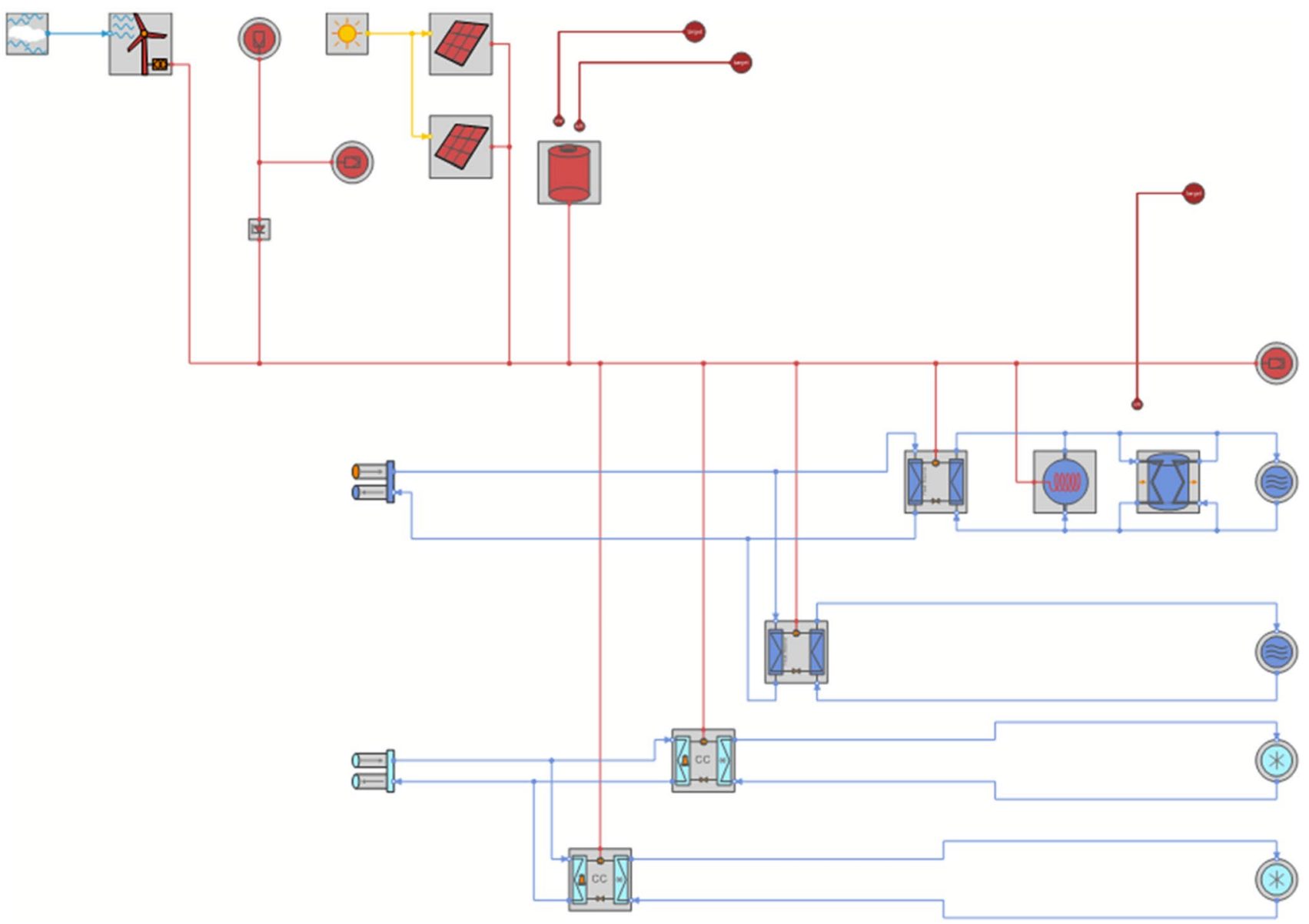

Fig. 13 Simulation model of the developed supply system implemented in top-energy. system components: electrical generation (upper left), building technologies (lower left), demands (right) and

of the possible output of the energy sources was utilized. The simulation demonstrated that the generation side of the baseline scenario is oversized. The costs for the baseline generation side were evaluated to be approx. EUR 5.6 million.

Due to this neither energetically nor economicallyviable result, the generation side of the hub was optimized with regards to its costs. Three alternative supply solutions were simulated and compared to each other. The result indicated that the most promising energy source configuration consists of a wind turbine, a PV-system on the roof of the accommodation building, and a battery with a storage capacity of $880 \mathrm{kWh}$ and a maximum charge/discharge power of $155 \mathrm{~kW}$. This configuration achieves a utilization ratio of $20.6 \%$. The costs for this solution are approx. EUR 2.5 million. storage system (middle). Types of energy: electricity (red), heat (dark blue) and cold (light blue)

\section{Conclusion and outlook}

In this paper, the basic design of the Energyhub was described for a location in the North Sea. The resulting module provides comfortable living and working conditions for a maintenance crew of 32 people along with space for spare parts and equipment, enabling the platform to perform maintenance of offshore gearless wind turbines with a capacity of up to $10 \mathrm{MW}$. The platform is equipped with a renewable energy-based energy supply system. The functionality of the system was verified by means of a simulation with a resolution of ten minutes. To run the simulation, the energy demands of the hub were evaluated as load profiles. Therefore, a load profile generator was developed as a Bottom-Up 
approach. Within the load profile generator, the demands resulting from behavior-triggered devices and actions are simulated on basis of predefined probability profiles. The thermal demands of the system were simulated on the basis of weather data and the technical characteristics of the building. The resulting load profiles exhibit a continuous shape, as can be expected due to the relatively constant schedules of the hub and its inhabitants. In detail, the occurring loads differ each day and exhibit extreme load situations, just as can be expected from the Energyhub. As a result of the simulation, an initial optimization level of the system could be achieved. To enhance the accuracy of the computed energy demands, a comparison with similar systems or at best even a prototype of the Energyhub should be performed. As a result, the efficiency of the energy supply systems could be increased by installations which meet the energy demands of the hub more specifically. The results of this study are adaptable to other offshore platform solutions if adequate load profiles are known and can be used as input data.

Acknowledgement These results arise from the project Space@Sea, which is funded by the Horizon 2020 research and innovation program of the European Union, under the Grant Agreement No. 774253

Funding Open Access funding enabled and organized by Projekt DEAL.

\section{Compliance with ethical standards}

Conflict of interest The authors declare that they have no competing interests.

Open Access This article is licensed under a Creative Commons Attribution 4.0 International License, which permits use, sharing, adaptation, distribution and reproduction in any medium or format, as long as you give appropriate credit to the original author(s) and the source, provide a link to the Creative Commons licence, and indicate if changes were made. The images or other third party material in this article are included in the article's Creative Commons licence, unless indicated otherwise in a credit line to the material. If material is not included in the article's Creative Commons licence and your intended use is not permitted by statutory regulation or exceeds the permitted use, you will need to obtain permission directly from the copyright holder. To view a copy of this licence, visit http://creativecommons.org/licenses/by/4.0/.

\section{References}

Durstewitz M, Berkhout V, Faulstich S, Görg P, Große L, Hahn B, Lutz M, Mayer J, Pfaffel S, Rehwald F, Spriestersbach (2019) Windenergie report Deutschland 2018. Report. FraunhoferInstitut für Energiewirtschaft und Energiesystemtechnik IEE, Kassel, Germany, ISBN 978-3-8396-1483-9 (reference in German language//English reference title: Wind Energy Report Germany 2018)
Frampton M, Lopes M (2018) Floating wind joint industry project-Phase I Summary Report, Report, Carbon Trust, London, England

Fünfgeld C, Tiedemann R (2000) Anwendung der Repräsentativen VDEW-Lastprofile step-by-step. Report, VDEW-Frankfurt, Frankfurt am Main, Germany M-05/2020 (reference in German language//English reference title: application of the representative VDEW load profiles step-by-step)

Global Offshore Wind Farms Database-4C Offshore (2020) Online Source, Available: http://www.4coffshore.com/windfarms/. Accessed on: Aug. 172020.

Lagerveld S, Röckmann C, Scholl M (2014) A study on the combination of offshore wind energy with offshore aquaculture. Report, IMARES Report Co56/14

Metz M (2014) Flexible energieversorgung-modellierung der lastund erzeugungssituation dezentraler versorgungsgebiete zur bestimmung der systemflexibilität. PhD Thesis. Fakultät Elektrotechnik und Informationstechnik, Technische Universität Dortmund, Germany (reference in German language//English reference title: flexible energy supply modeling of the load and generation situation of decentralized supply areas to determine system flexibility)

Miedema R (2012) Offshore wind energy operations and maintenance analysis. Research Thesis, Hogeschool van Amsterdam, the Netherlands

Pflugradt ND (2016) Modellierung von wasser- und energieverbräuchen in haushalten. PhD Thesis. Fakultät Maschinenbau, Technische Universität Chemnitz, Germany (reference in German language // English reference title: Modeling of water and energy consumption in households)

Röckmann C, Lagerveld S, Stavenuiter J (2017) Operation and maintenance costs of offshore wind farms and potential multi-use platforms in the Dutch North Sea. In: Buck B, Langan R (eds) Aquaculture perspective of multi-use sites in the open ocean (pp. 97-113). Springer https://doi.org/10.1007/978-3-319-51159-7

Schieferdecker B (1999) Repräsentative VDEW-Lastprofile. Report, VDEW-Frankfurt, Frankfurt am Main, Germany M-32/99 (reference in German language // English reference title: Representative VDEW load profiles)

Stokes M (2005) Removing barriers to embedded generation: a finegrained load model to support low voltage network performance analysis. PhD Thesis. Institute of Energy and Sustainable Development, De Montfort University, Leicester, England

Whiteman A, Esparrago J, Rueda S, Elsayed S, Arkhipova I/IRENA (2019) Renewable capacity statistics 2019. In: Report, International Renewable Energy Agency (IRENA), Abu Dhabi, ISBN 978-92-9260-123-2

Widén J, Lundh M, Vassileva I, Dahlquist E, Elleård K, Wäckelgård E. (2009) Constructing load profiles for household electricity and hot water from time-use data-modelling approach and validation. Energy and Building, 41.7: 753-768 (Elsevier) https://doi.org/10. 1016/j.enbuild.2009.02.013

Publisher's Note Springer Nature remains neutral with regard to jurisdictional claims in published maps and institutional affiliations. 